\title{
A ANTEPOSIÇÃO DOS ADJETIVOS PREDICATIVOS NO PORTUGUÊS CULTO FALADO NO BRASIL*
}

\author{
José da Silva Simões
}

\begin{abstract}
RESUMO: Neste artigo, tratamos da anteposição dos adjetivos no português brasileiro (pb) falado culto na cidade de São Paulo com base nos arquivos do Projeto NURC-SP. O estudo baseia-se na tipologia proposta por Ilari (1990 e 1992) e Castilho (1990) para a categorização dos advérbios em português. O fenômeno da anteposição dos adjetivos foi analisado com o suporte da teoria da variação e levou em conta a análise multiregressiva das variantes anteposição $v s$. posposição de adjetivos. Na primeira parte do texto, traçamos um pequeno histórico a respeito da questão da ordem em pb segundo o estudo de Tarallo (1990). Em seguida, apresentamos uma proposta de tipologização dos adjetivos predicativos em três categorias: quantificadores, aspectualizadores e modalizadores segundo o modelo de Castilho (1992). Na parte final do artigo, discutimos os resultados da análise multiregressiva e do cruzamento dos grupos de fatores estabelecidos para a quantificação dos dados. Na conclusão, reunimos comentários acerca dos fatores que favorecem a anteposição de adjetivos predicativos em $\mathrm{pb}$.
\end{abstract}

PALAVRAS-CHAVE: Português Brasileiro falado; Adjetivos Predicativos; Operadores de Modalização; Gramática Funcional - ordem de palavras.

INTRODUÇÃO

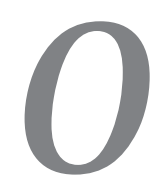

presente trabalho pretende tratar da questão da posição pré e pós-nominal dos adjetivos predicativos na linguagem falada culta de São Paulo. Como base para o estudo dos predicativos, tomamos as considerações a

\footnotetext{
Este artigo é fruto de uma monografia entregue ao Prof. Dr. Ataliba Teixeira de Castilho por ocasião de seu curso A Sintaxe do Adjetivo oferecido em nível de pós-graduação durante o primeiro semestre de 1992 na área de Língua Portuguesa da USP.

" Universidade de São Paulo.
} 
SIMÕES, José da Silva. A anteposição dos adjetivos predicativos no português culto falado...

respeito dos advérbios feitas na Gramática do Português Falado (Castilho,1990 e Ilari, 1992). Fazem parte do corpus de análise as 21 entrevistas transcritas do projeto NURC-SP:

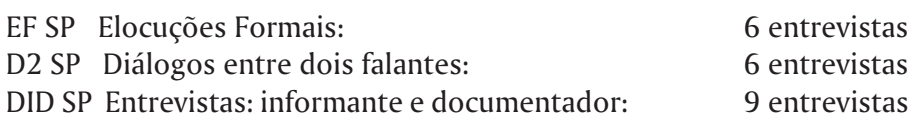

Através de uma abordagem quantitativa dos dados recolhidos nas entrevistas, feita a partir do programa estatístico VARBRUL, procuramos responder as seguintes questões básicas sobre a ordem dos adjetivos predicativos no português falado:

1. Quais os mecanismos que influenciam a escolha do falante para a colocação pré ou pós-nominal dos adjetivos predicativos, uma vez que a questão da ordem dos adjetivos no português contemporâneo apresenta-se predominantemente no esquema NA (Nome + Adjetivo)?

1.1. Que categorias, que tipos de adjetivos predicativos, sobressaem-se na escolha AN (Adjetivo + Nome)?

2. Em que medida a natureza do nome favorece o arranjo AN e/ou NA?

3. Em que medida o lugar do sintagma nominal $(\mathrm{SN})$ e sua fronteira argumental em relação ao verbo influencia na ordem e na escolha de determinadas categorias de adjetivos predicativos?

4. Que elementos influenciam na organização dos SNs ANA (sanduíches adjetivais)?

5. Em que medida a natureza do verbo influencia na escolha e ordem dos Adj predicativos?

6. A dimensão silábica do adjetivo influencia a ordem?

7. A repetição influencia a ordem dos Adj predicativos no SN?

8. A Natureza contável ou não-contável do $\mathrm{N}$ influencia a ordem dos Adj predicativos no SN? 
9. Em que medida a questão da tessitura do adjetivo influencia a ordem do mesmo no SN?

Inicialmente, levamos em consideração as observações feitas por Tarallo e Kato (1990) a respeito da questão da ordem no português falado, numa perspectiva histórica da língua, uma vez que o português tenha se transformado, em sua última fase, de uma língua do modelo SOV, acompanhando o modelo latino, para uma língua SVO, e quais os resquícios daquele modelo poderiam ainda estar influenciando na ordenação distribucional dos elementos na frase do português.

Os estudos de Ilari (1990 e 1992) na Gramática do Português Falado prevêem uma categorização dos advérbios predicativos que foram adaptados por Castilho (1992) para o estudo dos adjetivos. Os predicativos estariam, assim, distribuídos em três grupos: os qualitativos, os quantitativos e os modalizadores e suas subcategorias. Tentamos aqui encaixar os exemplos recolhidos seguindo essa categorização. No entanto, no decorrer da análise, percebemos que, assim como foi notado por Castilho (1992), existe uma flutuação categorial gerando casos limítrofes, o que de certa forma poderia comprometer a perspectiva quantificadora dos dados recolhidos. Por esse motivo, achamos prudente discorrer a respeito dos casos que parecem não se comportar como exclusivamente integrantes de uma única categoria. Estão envolvidas nessa questão da flutuação categorial elementos cuja categorização fica comprometida, uma vez que existem dúvidas quanto às propriedades quantificadora, delimitadora (hedge), intensificadora, focalizadora e modalizadora.

Na fase final do trabalho, precavendo-nos de possíveis erros indicados pelo exposto acima, partimos para a análise quantificadora dos dados, onde são apresentados os resultados estatísticos produzidos pelo pacote de programas VARBRUL. 
SIMÕES, José da Silva. A anteposição dos adjetivos predicativos no português culto falado...

Para a análise mais profunda do fenômeno da anteposição, procuramos nos ater à coleta de adjetivos com aderência argumental mais aproximada ao nome, a fim de analisarmos de que forma os adjetivos predicativos transitam de uma para outra posição e quais elementos podem influir para tanto. Dessa forma, selecionamos um conjunto de grupos de fatores que poderiam influenciar o favorecimento da anteposição ou da posposição dos adjetivos predicativos. As variáveis independentes são, então:

1. Tipo do adjetivo predicativo (NURC)

2. Tipo de entrevista (DID-EF-D2)

3. Entrevistado/Documentador

4. Faixa etária

5. Sexo

6. Escolaridade

7. Natureza do nome

8. Unidade sintática analisada (SN ou SP)

9. Lugar argumental na fronteira verbal

10. Natureza do verbo

11. Natureza do preenchimento com especificadores e complementos

12. Tipo dos especificadores

13. Tipo dos complementos

14. Natureza de número do preenchimento com especificadores e complementos

15. Sanduíches adjetivais

16. Lugar argumental dentro das fronteiras do SN

A coleta dos dados foi abrangente e recolhemos todos os exemplos com aderência argumental imediata, não nos importando $a$ priori com a possibilidade de variação ou não do exemplo recolhido 
segundo a pré ou posposição nominal. A varredura segundo a variável dependente anteposição vs. posposição só foi efetuada posteriormente, uma vez que num primeiro momento precisávamos definir mais exatamente todos os exemplos recolhidos segundo a categorização semSântica, para só então submetê-los à análise estatística.

\section{A QUESTÃO DA ORDEM NO PORTUGUÊS FALADO}

Tentaremos através deste capítulo fazer um apanhado geral a respeito da questão da ordem dos elementos e como ela vem sendo analisada por alguns autores, de maneira geral e também especificamente em relação ao português. Assim, os subtópicos que se seguem são pequenas apresentações dos textos por nós selecionados e que serviram de base para o nosso estudo.

\subsection{Fernando Tarallo: A ordem das palavras no português falado}

Tarallo (1990) expõe em seu trabalho o percurso da língua portuguesa do nível sintético para o analítico, baseando-se em estudos feitos sobre a evolução do português a partir do latim clássico, passando pelo latim vulgar, pelo português arcaico e a sua atual configuração.

Ele discorre a respeito da sintaxe de colocação, fenômeno que não existia no latim clássico, uma vez que a função dos elementos na oração já estivesse marcada através de casos, permitindo a maior flexibilidade na ordenação dos elementos constituintes. A ordem aí era determinada "relativamente fixada por fatores de natureza estilística, mas não gramatical” (Tarallo, 1990,p. 148). Também segundo Câmara Junior (1976), a ordem no português, ao contrário do francês, fixou-se entre dois pólos: o gramatical e o estilístico. Há, portanto, certa maleabilidade na ordenação dos elementos, mas a colocação do nível estilístico estaria, no entanto, submetida às regras gramaticais. 
SIMÕES, José da Silva. A anteposição dos adjetivos predicativos no português culto falado...

Tarallo também fala a respeito da distribuição dos adjetivos nos sintagmas nominais:

\begin{abstract}
Na expansão dos sintagmas nominais em português cabe ao adjetivo a última posição: a menina bonita, o menino inteligente. O que rege essa posição do adjetivo é, segundo Câmara Junior, um fator de ordem funcional: 'Há um princípio básico, que consiste em atribuir ao último termo do enunciado o máximo valor informativo' [Câmara Junior, 1976: 250]. Mas Dentro do sintagma nominal, o adjetivo também pode aparecer anteposto ao substantivo. Não se trata, pois, de uma ordem rígida, gramaticalmente fixa; trata-se, sim, de uma ordem menos marcada (no sentido de mais comum), com o adjetivo posposto, posição essa determinada por um princípio básico do sistema, que é o de apresentar a informação nova no fim dos predicados (núcleos): nominais e/ou verbais. Assim, 'a posposição é (...) a pauta fundamental, porque a função usual do adjetivo é acrescentar um dado de informação nova a respeito do substantivo; é essencialmente um elemento descritivo suplementar para a significação contida no substantivo [Câmara Junior, 1976: 251]. (Tarallo, 1990, p. 148-9).
\end{abstract}

Ele alerta ainda para o fato de que "isso não significa que à posposição cabe sempre a função não-marcada, e à anteposição, a função estilística. No caso dos adjetivos essencialmente qualificativos, a anteposição carrega, é verdade, a função estilística (marcada em relação à ordem básica dos constituintes dentro do sintagma nominal)", o que não aconteceria com os adjetivos demonstrativos, cuja ordem não-marcada é a anteposição. Para a sentença a ordem não-marcada é sujeitoverbo-objeto.

O autor conclui, portanto, que a gramática determina, através de suas regras, a configuração não-marcada da ordem das palavras e "que sobre essa se imporá o princípio funcional que atribuirá colorações estilísticas diferenciadas aos enunciados na medida em que a ordem básica é quebrada" (Taralo, 1976, p. 149-50).

Essas considerações são de extrema importância para o escopo da pesquisa proposta por nós. Através delas podemos enxergar os mecanismos que regem a anteposição dos adjetivos como função marcada não só com valor estilístico, mas também com explicações na origem e evolução da língua portuguesa. Historicamente 
ficou comprovado que o latim arcaico e popular apresentavam a ordem era objeto-verbo-sujeito, e que o clássico apresentava preferencialmente a ordem sujeito-objeto-verbo, e que a ordem sujeito-verbo-objeto constitui a forma mais nova do português. Daí podermos concluir que ainda ocorre uma flutuação na ordem dos adjetivos, cuja anteposição fica marcada não só na língua falada como também, e de forma bastante notada, na língua literária.

\section{A CATEGORIZAÇÃO DOS ADJETIVOS PREDICATIVOS}

Neste trabalho seguimos basicamente a taxionomia proposta por Castilho (1992). A nomenclatura está fundada nos estudos feitos a respeito dos advérbios predicativos na linguagem falada culta. Como foi exposto no prefácio deste estudo, a categorização foi testada através dos exemplos recolhidos por nós nas entrevistas realizadas em São Paulo pelo Projeto NURC, o que de certa forma evidencia uma determinada insegurança quanto à aplicação estanque da terminologia proposta. Com o propósito de lançar os problemas em aberto a uma discussão posterior, tentaremos enumerar aqui os casos limítrofes, cuja flutuação categorial se manifestou durante a análise semântica dos dados.

Para entender melhor a proposto feita por Castilho (1992) é preciso retomar Ilari $(1990$, p. 89$)$ e suas considerações a respeito do que se entende como advérbios predicativos:

Na afirmação tradicional de que o advérbio modifica tipicamente o sentido do verbo ou do adjetivo está implícita a hipótese de que ele expressa uma espécie de predicação de grau superior: assim como o verbo ou o adjetivo atribuem uma ação ou uma propriedade ao sujeito, o advérbio predicaria uma propriedade da qualidade ou ação que se atribui ao sujeito.

Para Ilari, o núcleo significativo do verbo e do adjetivo é afetado pelo acréscimo de advérbios predicativos como bem, muito e autenticamente, ou seja, há "qualificação, intensificação, alterando aquele núcleo", ao passo que o núcleo do sentido dos verbos e do adjeti- 
SIMÕES, José da Silva. A anteposição dos adjetivos predicativos no português culto falado...

vos permanece intacto na ocorrência de um advérbio não-predicativo como aqui, cedo, não e inclusive (Ilari,1990, p. 90).

Podemos adaptar esses raciocínios para a distinção entre os adjetivos predicativos e não-predicativos da seguinte maneira: enquanto o núcleo significativo de um nome (N) é afetado pelo acréscimo de adjetivos predicativos tais como grande, imenso, pequeno, sendo assim qualificado, intensificado ou modalizado, por outro lado, na ocorrência de um adjetivo não-predicativo do tipo verificador como quarenta, diverso, total, o núcleo significativo de $\mathrm{N}$ permanece intacto, pois a ele foi agregada apenas uma propriedade de afirmação ou negação, de inclusão ou exclusão ou mesmo focalização sobre o conteúdo do mesmo.

Uma vez assumida a diferenciação entre adjetivos não-predicativos e os meramente predicativos, passamos a descrever na seção seguinte a terminologia proposta por Castilho (1992).

\subsection{Os adjetivos predicativos qualitativos}

Os predicativos qualitativos se subdividem em (i) qualitativos não-psicológicos (ii) e os qualitativos psicológicos.

(i) os qualitativos não-psicológicos predicam somente o referente do $\mathrm{N}$ :

(1) e aparece também uma belíssima senhora... (EF SP 153)

(2) Manuel Bandeira que (...) é um excelente crítico de artes plásticas (EF SP 156: 57)

(3) e ao lado, então, dos ricos Ademar Gonzaga e Carmen Santos, então, viceja [?], não é? (EF SP 153: 251) 
Filol. lingüíst. port., n. 8, p. 145-189, 2006.

(4) na minha época havia as famosas perspectivas de ponto de fuga (EF SP 124: 96)

Entre os qualitativos não-psicológicos encontramos ainda rapidíssima, rápido, curto, célebre, bom, bonito, mau, péssimo, novo, potente, clássico, raro, raríssimo, belo, velho, tolo, vil, melhor e exímio.

(ii) Os predicativos qualitativos psicológicos predicam concomitantemente o referente do $\mathrm{N}$ e o falante/interlocutor. Originalmente Castilho (1992) propôs a ordenação destes aos modalizadores uma vez que o aspecto da posição do falante em relação às propriedades da proposição fica bastante evidente. Pretendemos adiante discutir a possibilidade de reordenação dos psicológicos aos modalizadores:

(5) por estranha coincidência passaram-se mais alguns anos e pegou fogo no mercado velho (DID SP 208: 281)

(6) agora o lado discutível escapa à televisão, que é aquele lamentável lado do Baú [da Felicidade] (D2 SP 333:1094)

\subsection{Os adjetivos predicativos quantitativos}

Os predicativos quantitativos compreendem três subtipos: (i) os mensuráveis, (ii) os intensificadores e (iii) os aspectualizadores. Os (i) estão ligados à quantificação das formas e noções de mensuração de distâncias. Já os (ii) intensificadores se caracterizam por predicarem processos, estados, sentimentos e capacidades e ainda relações e denotam uma dimensão não discreta do $\mathrm{N}$. Talvez por estarem ligados à noção não só de intensificação daquilo que é definidamente mensurável e sim de outras categorias intensificáveis (processos, relações, sentimentos e estados) é que seria interessante discutirmos a validade de incluirmos a intensificação como uma subcategoria exclusiva dos quantificadores, uma vez que pelo ex- 
SIMÕES, José da Silva. A anteposição dos adjetivos predicativos no português culto falado...

posto ela também pode se estender à modalização. Os (iii) aspectualizadores, por outro lado, predicam a relação de mensuração do tempo e estão subdivididos em aspectualizadores definidos e aspectualizadores indefinidos. É interessante notar que não encontramos exemplos em anteposição dos aspectualizadores definidos o que nos permite dizer que estes, por serem os /-prototípicos/ dentre os predicativos, estariam semanticamente mais perto dos não-predicativos, assim como os dêiticos de tempo. Em geral, os aspectualizadores predicam indicando a frequiência com que um evento se reitera. Daí o fato de estarem normalmente ligados a $\mathrm{N}$ deverbais.

(i) a. Quantificadores mensuráveis unidimensionais: predicam de forma definida a dimensão do $\mathrm{N}$ :

(7) depois o chão era tudo de tábua larga (DID SP 018: 13)

(8) ela era uma casa antiga tipo colonial brasileiro, janelas largas (DID SP 018: 10)

Outras ocorrências de Mensuráveis Unidimensionais são: alto, baixo, curto, longo, raso, fundo, etc.

(i) b. Quantificadores mensuráveis não-unidimensionais: predicam de forma indefinida a dimensão do $\mathrm{N}$ :

(9) então o pessoal já está esperando mancada dos artistas e uma coisa de baixa qualidade (DID SP 161: 108)

(10) vamos fazer assim uma pequena excursão com a família, né? (D2 SP 255: 376)

Também encontramos as seguintes ocorrências de Mensuráveis Não-Unidimensionais: maior, baixos (ansiosos), e mínimo. 
Filol. lingüíst. port., n. 8, p. 145-189, 2006.

\section{(ii) Quantificadores intensificadores:}

(11) [a gente] vai divisar no século dezoito nas grandes marinhas de Joseph [Vermeer]. (EF SP 156: 641)

(12) os jornais cariocas registraram com extraordinária freqüência a estupefação causada... (EF SP 153: 687)

(13) e nestas condições é assim com grande ansiedade que eu vejo a semana passar, principalmente uma semana de dias bonito (D2 SP 25: 363)

(14) então o telefone estaria cumprindo um espetacular papel assim, não é? (D2 SP 255: 915)

(15) também ocorreu uma grande mudança no nível do aluno (D2 SP 255:1193)

Outros exemplos de Intensificadores são: imenso, alto (nível intelectual), notável (liberdade de expressão), extrema (precisão do desenho), enorme (ventura), profunda (identidade de interesses), eminentes (tradições), bela (cidade $=$ grande cidade) e lindo (pernil = grande pernil).

(iii) a. Quantificadores aspectualizadores definidos:

(16) a renda mensal é igual ... mil e duzentos... (EF SP 388: 131)

(17) sem termos anuais interessa saber então relacionar essa demanda de moeda (por) transações com o nível de renda em termos... (EF SP 388: 127)

(iii) b. Quantificadores aspectualizadores indefinidos:

(18) [a gente] não pode aceitar essa arte que ensina a (...) eterna briga contra os que têm direito de mandar... (EF SP 153: 882)

(19) nos sucessivos governos ele continuou como assessor do Secretário (D2 SP: 360: 841) 
SIMÕES, José da Silva. A anteposição dos adjetivos predicativos no português culto falado...

Identificamos ainda os seguintes exemplos de aspectualizadores indefinidos: menor (freqüência), maior (participação), eterno (presente) e infinitos (recursos técnicos).

\subsection{Os adjetivos predicativos modalizadores}

Num estudo sobre a modalização presente nos advérbios predicativos, Castilho (1992) aponta para "a importância do modo na estruturação e na interpretação semântica das sentenças" (1992, p. 217). Trata-se de uma qualificação do conteúdo da forma de $\mathrm{P}$, de acordo com o julgamento do falante.

Esse julgamento se expressa de dois modos: (1) o falante apresenta o conteúdo proposicional numa forma assertiva (imperativa ou optativa), interrogativa (polar ou não-polar) e jussiva (imperativa ou optativa); (2) o falante expressa seu relacionamento com o conteúdo proposicional, avaliando seu teor de verdade, ou expressando seu julgamento sobre a forma escolhida para a verbalização desse conteúdo (Castilho, 1992, p. 217).

No mesmo artigo, Castilho engloba os advérbios afetivos (psicológicos) entre os modalizadores, o que daria crédito à nossa hipótese de reordenação dos predicativos psicológicos junto aos modalizadores, uma vez que modalizar se caracteriza pela maneira de ser peculiar de cada indivíduo, que expressa seus conceitos segundo a sua crença (epistemógico), segundo o domínio de seus conhecimentos (hedge, delimitador) e segundo uma moral (deôntico).

Assim, os modalizadores caracterizam, em geral, de um modo subjetivo, veiculando uma avaliação do falante sobre o conteúdo do N. Afirma-se, então, que esses adjetivos são orientados para o falante, onde "a resultante composicional põe de lado as características objetivas desses indivíduos, para realçar o fato de que o falante as assume como uma avaliação própria" (Castilho, 1992).

\section{(i) Predicativos modalizadores epistêmicos}


Filol. lingüíst. port., n. 8, p. 145-189, 2006.

(i) a. Modalizadores epistêmicos asseverativos: o falante toma o escopo da proposição inerente ao nome e afirma, através do predicativo, que as suas propriedades são verdadeiras:

(20) eu tenho verdadeira veneração por tudo, mesmo por aquilo que eventualmente de dissabor ele possa causar (D2 SP 255: 324)

(21) eu notei que o homem era assim profundo conhecedor de quem era os ministros e de atos do governo (D2 SP 255: 688)

(22) tem peças que são autênticas porcarias (DID SP 161: 255)

Foram detectados ainda os seguintes epistêmicos asseverativos: falso, principal limitados (conhecimentos).

(i) b. Modalizadores epistêmicos quase-asseverativos: indicam uma insegurança do falante em relação à validade de P:

(23) a manta por dentro protege o pêlo do cavalo de uma possível machucadura causada pelo arreio (DID SP 018: 756)

(24) quando ao lado desta possível promoção comercial que (...) se pretende ou se faz do rádio um veículo como o R. salientou muito bem (D2 SP 255: 736)

\section{(ii) Modalizadores delimitadores hedges}

Os delimitadores hedges são também chamados de quasemodais uma vez que delimitam, circunscrevem, limitam o ponto de vista sob o qual P pode ser considerada correta. Segundo Castilho (1992, p. 222) "os delimitadores têm um força ilocucionária maior que os Asseverativos e os Quase-Asseverativos, pois implicitam uma negociação entre os interlocutores, necessária à manutenção do diálogo".

(ii) a. Modalizadores delimitadores definidos 
SIMÕES, José da Silva. A anteposição dos adjetivos predicativos no português culto falado...

(25) esse mercado (...) estava num completo caos. Um completo caos provocado pela revolução do cinema falado (EF SP: 153: 56)

(26) porque representa (...) um estado assim de marginalização da pessoa, ela ser inserida (...) numa total ausência, entende? de integração (D2 SP 255:1019)

(27) então existe uma íntima ligação, né? estudante-empresa, professor-empresa (D2 SP 343:1588)

(28) eu sou uma má católica (DID SP 362)

(29) os livros eram especializados em diferentes matérias (DID SP 242: 72)

(30) bom como boa italiana (...) gosto de macarrão (DID SP 235: 217)

(ii) b. Modalizadores delimitadores indefinidos:

(31) as nossas emissoras solicitadas exportavam apenas o texto que era depois traduzido e feito em diversos países pelos artistas locais (D2 SP 333: 469)

(32) hoje a televisão com aquela sua telinha mágica que leva a figura, que leva a imagem, contando as histórias para as mais diversas regiões do país, né? (D2 SP 333: 952)

Entre os delimitadores indefinidos destacamos as presenças também dos predicativos certo e determinado, cuja ordem nãomarcada é exclusivamente a da anteposição. Daí não termos exemplos, uma vez que não apresentam variação.

(iii) Modalizadores deônticos: onde o conteúdo de $\mathrm{P}$ deve ocorrer obrigatoriamente. Uma vez que não temos exemplos em anteposição, citamos alguns exemplos de posposição:

(33) eles não fornecem com a presteza necessária que se chama um extrato de conta (DID SP 250: 483) 
Filol. lingüíst. port., n. 8, p. 145-189, 2006.

(34) o esquema vai evoluindo sempre e arranjando peças, criando peças novas. Vão distribuindo funções necessárias (D2 SP 343: 957)

(35) [d]a filosofia grega que foi um dos componentes essenciais do Cristianismo, compreende? (EF SP 124: 142)

(36) mas eu considero o automóvel face às condições do transporte urbano, como sendo um dos bens indispensáveis à minha vida (D2 SP 255: 187)

\subsection{Os casos limítrofes: a flutuação categorial \\ 2.4.1 Ferris: os adjetivos predicativos separativos}

Num artigo sobre a referência temporal nos adjetivos em inglês, o estudioso Connor Ferris (1991) trata também da questão dos adjetivos de qualificação separativa. As considerações feitas nesse artigo são importantes para a nossa pesquisa, pois o mesmo aborda questões ligadas à flutuação dos adjetivos predicativos que transitam entre os quantificadores, os intensificadores e os modalizadores.

Uma vez que os adjetivos de referência temporal pontual e, portanto, dêiticos são meramente não-predicativos, achamos oportuno concentrarmo-nos tão-somente nos adjetivos aqui chamados de separativos. Existe em nosso corpus um volume bastante grande de exemplos cuja categorização fica muito comprometida, uma vez que se tratam de predicativos que transitam entre as categorias acima citadas. Mesmo dentro da categoria dos modalizadores parece haver uma gradiência insustentável entre os epistêmicos e os delimitadores, tornando a categorização mais complicada ainda.

Pelos motivos acima abordados, achamos pertinente discorrer a respeito da categorização proposta pelo autor (Connor Ferris) que de certa forma vem a coincidir com a subcategorização propostas por Rodolfo Ilari (1992) a respeito dos advérbios focalizadores no português. 
SIMÕES, José da Silva. A anteposição dos adjetivos predicativos no português culto falado...

Ferris (1991) discorre assim a respeito dos predicativos separativos:

What these adjectives do qualify is neither the description provided by the noun nor the designated entity, nor the complex made up of the two taken together, but the RELATION between the entity which is seen as a participant in the structure of the sentence communicated, and the description which characterizes and identifies that entity. (Ferris, 1991, p. 578)

Ao lado dos separativos temporais, Ferris aponta ainda para a ocorrência de outros separativos não-temporais:

Other nontemporal adjectives that can act separatively all seem to have a potential ambiguity of relation; while they can be used separatively in some instances, they also have another use in which they qualify standardly; this indeed is true of old, already cited. That, however is no inconvenience since it can help to make up us more aware of the distinction. Thus apparent usually acts as a separative, as in a phrase like (25).

(25) the apparent leader held a gun

It is not the individual as such who is only 'apparent', but the fit of this description as leader. At the same time apparent has a less common but perfectly acceptable use as a standard adjective, when it is approximately equivalent to evident, as in (26):

(26) Ivan's readlily apparent anger dismayed her" (Ferris 1991, p. 581-2)

Exemplos de outros separativos, segundo Ferris, seriam aparente, ocasional, possível, verdadeiro, velho entre outros. Seguem-se os exemplos:

(1) the apparent leader held a gun

(2) Ivan's readly apparent anger dismayed her

(3) Herr Dittersdorf is a possible ally

(4) Lucian was a true modernist

(5) the WHO has already sent medical teams to deal with possible cholera outbreaks

(6) Gaston told us a true story about his uncle

(7) an occasional sailor strolled by

(8) she met Anna on one of her occasional visits to Rome 
Filol. lingüíst. port., n. 8, p. 145-189, 2006.

Naturalmente, segundo as considerações feitas nos estudos da Gramática do Português Falado (vol. I e vol. II) os exemplos (1)-(6) teriam o seu lugar assegurado entre os modalizadores epistêmicos e (7) e (8) seriam aspectualizadores indefinidos. No entanto, preferimos apresentar aqui, a título de teste da terminologia proposta, uma confrontação com outras posições, como as de Ferris e de Ilari.

Ferris reconhece, a partir de inferências, que o fato da presença dos separativos não se restringe exclusivamente ao inglês:

\begin{abstract}
Are adjectives of this sort peculiar to English? The syntactic 'shape' of their pecualirity does not look like something which is language-specific, and our interpretation of adjetives which wold correspond translationally in one or two other languages makes us very confident that this type of qualification is a feature of language in general. (Ferris, 1991, p. 583)
\end{abstract}

$\mathrm{O}$ argumento mais forte para a existência dos separativos como classe em si surge no final do artigo:

As we have just remarked, the predicative adjective is syntactically applied to the subject of the sentence. But the subject of a sentence cannot be merely a relation between two parts of itself; it has to be taken as the whole made up of the lexical description, the entity that we should not expect to find a separative adjective in predicative position. (Ferris, 1991, p. 588)

Uma vez que aqui está incluída a ocorrência do adjetivo "ocasional" podemos afirmar que Ferris engloba no escopo dos separativos alguns aspectualizadores. Naturalmente os assim separativos teriam uma organicidade interna a ser discutida.

\title{
2.4.2 Rodolfo llari: a questão da focalização
}

De outro lado, Rodolfo Ilari (1992) também reconhece este aspecto de confronto entre as categorias de intensificação, de modalização e de focalização. A partir de exemplos de advérbios predicativos e não-predicativos, ele propõe uma taxionomia provisória para aquilo que ele chama de "operações de verificação" das 
SIMÕES, José da Silva. A anteposição dos adjetivos predicativos no português culto falado...

propriedades implicadas - aqui tomamos os exemplos para o escopo da questão dos adjetivos predicativos:

\subsubsection{Verificação de número}

A verificação de número ocorre quando se supõe uma contagem, apontando um número como resultado de uma operação específica:

(37) em média a retenção média para satisfazer os seus gastos as suas transações normais, os seus pagamentos normais, aqui evidentemente é mais para efeito didático a gente fez uma coisa assim, todo mundo sabe que a gente vai gastar quarenta cruzeiros todo dia, bonitinho, certo? (EF SP 124: 183)

(38) eu acho que tudo o que você tem de material tem um valor simbólico, sabe? (D2 SP 343: 721)

Em (37) temos o reforço do valor numérico (grifo nosso) atestando a hipótese de médio como referência a um resultado de operação específica. Já em (38) simbólico apela para uma responsividade do interlocutor, reforçada pelo marcador sabe?.

Também em (31), apesar de ficar vaga a noção do número, o falante certamente trabalha com a verificação numérica em diversos países $(=$ mais de 1$)$.

\subsubsection{A verificação de proporção}

Uma das características da focalização para Ilari seria o fato de poder-se entender que podemos entender as propriedades e as relações (aqui expressas por nomes) ao realizarem-se "em parte" ou "por inteiro", o que equivale a dizer que estamos lidando aqui com a totalidade das propriedades intensionais do N, cujo grau de reali- 
Filol. lingüíst. port., n. 8, p. 145-189, 2006.

zação pode ser "medido" entre .0 e 1.0 , se pensarmos em termos estatísticos.

(39) eles conseguem chegar a uma fidelidade linear da natureza, à extrema exatidão do desenho ou precisão (EF SP 405: 392)

(40) a televisão passa a ser um total desvirtuamento, não é? (D2 SP 255: 670)

Nesse caso, podemos incluir também os elementos "certo" e "determinado" como indicadores de média realização das propriedades do N.

\subsubsection{Verificação de coincidência com um protótipo}

Os focalizadores podem, segundo Ilari, apresentar "uma propriedade ou relação realizando-se de maneira 'prototípica' ou 'exemplar" (Ilari, 1992: 201). É o caso dos seguintes exemplos:

(41) a gente lamenta muito profundamente essa característica comercial da televisão desvinculando aqueles verdadeiros objetivos que seriam objetivos de educar, seriam objetivos de aconselhar, seriam objetivos até mesmo de orientar, eu suponho ((D2 SP 255: 604)

(42) é tão raro que o ator nosso tenha esses dois predicados: saiba interpretar e tenha uma boa voz e conhecimentos musicais (D2 SP 333: 594)

(43) [o ator] ele tem que compreender o personagem para ele saber interpretar e ter uma boa interpretação (DID SP 161: 723)

(44) bom artista é o que desempenha o papel na peça de acordo com o que ele está fazendo (DID SP 234: 76)

Em todos os exemplos acima, bem como em outros anteriormente citados, (28) má católica e (29) boa italiana, o índice de verifi- 
SIMÕES, José da Silva. A anteposição dos adjetivos predicativos no português culto falado...

cação de prototipicidade fica evidente na medida em que o próprio falante reforça esta idéia, demonstrando como seria o protótipo:

(28a) para uma católica eu sou má

(29a) toda italiana gosta de comer macarrão, portanto eu sou uma boa italiana

(41a) os objetivos a serem alcançados são X,Y,Z e estes são os verdadeiros

(42a) um bom ator está para uma boa voz

(43a) interpretar significa $X$

(44a) é artista quem faz X

\subsubsection{Verificação de identidade e congruência}

Por meio desse tipo de verificação avalia-se, através dos predicativos, não a coincidência com um protótipo implícito, como nos exemplos acima, mas a coincidência com indivíduos, lugares e momentos explicitados no próprio texto. Não encontramos no corpus exemplos que pudessem ser ordenados a esse tipo de verificação. Talvez isso se deva ao fato de que a especificação sirva tão-somente para os advérbios:

(45) Está aí, bem exatamente a diferença: é uma predição, é uma inferência, a partir da constatação de uma identidade. [POA 278:218] (in Ilari, 1992, p. 204)

(45a) Está aí, em termos bem exatos a diferença: (...)

\subsubsection{Verificação de factualidade}

Esse tipo de verificação ocorre normalmente com o adjetivo predicativo real e com o advérbio realmente, cuja ocorrência decor- 
Filol. lingüíst. port., n. 8, p. 145-189, 2006.

re "de uma espécie de 'demonstração formal" (Ilari, 1992, p. 204). Através da análise de uma dada situação, o falante pretende realçar $P$, mostrando que possíveis posições contrárias estariam em concorrência com as "verdadeiras" noções de N. Daí falar-se de um jogo entre verdade e aparência. $\mathrm{O}$ uso destes predicativos dá a $\mathrm{P}$ o valor de sentido de convencimento e, portanto, retóricos. (46) Parece ser um exemplo bastante feliz, uma vez que engloba a ocorrência de ambos $o$ adjetivo e o advérbio:

(46) então, veja bem: os testes têm como objetivo verificar a situação real do indivíduo. Eu quero saber realmente do que esse indivíduo é capaz (EF SP 377: 26)

\subsubsection{A Questão da quantificação}

Os artigos publicados em torno da Gramática do Português Falado dissociam em primeira instância as noções de intensificação e de aspecto do âmbito da quantificação (Ilari, 1990). Por outro lado, Castilho (1992a) engloba tanto uma quanto a outra no escopo da quantificação.

É inegável que podemos depreender da noção de intensificação um certo valor de mensuração, mas isto nem sempre é aplicável para todos os casos em que a intensificação se faz presente. Vejamos os seguintes exemplos:

(47) [tudo isso]... é praticamente o meu grande hobby e eu vejo com muita felicidade que os meus filhos e a minha mulher... (D2 SP 255: 358)

(48) para ele, então, a história deste período e a história da imensa revolução que o homem estava... (EF SP 156: 369)

(49) [existir um jornal como NP] representa assim o agravemento de um estado assim de marginalização da pessoa [que aprende a 
SIMÕES, José da Silva. A anteposição dos adjetivos predicativos no português culto falado...

ler para depois ler NP] (...) se ver inserida naquele mundo de violência e sexo (...) e numa total ausência entende? de integração dentro dos grandes problemas da sociedade, dos grandes valores, entende? (D2 SP 255:1021)

Principalmente em relação a processos (48), sentimentos e avaliações (47 e 49), fica difícil enxergar o nível de mensuração, de quantificação. Talvez pudéssemos, assim como para os advérbios, dissociar a intensificação da quantificação, por apresentar-se como um fenômeno à parte, principalmente se o confrontarmos com exemplos de atenuação, como:

(50) eu acredito que é mais importante para nós, pararmos um pouco na meditação do sistema de Arte que ele estabeleceu, do que em pequenas manifestações esporádicas (EF SP 156; 21)

(51) embora eu não tenha a mínima vocação para isso (DID SP 250: 435)

\section{A QUANTIFICAÇÃO DOS DADOS: A ANTEPOSIÇÃO DOS PREDICATIVOS}

Através de uma abordagem estatística dos exemplos recolhidos por nós, tentaremos responder as questões propostas por nós no início deste artigo. É preciso, no entanto, esclarecer alguns pontos de ordem prática:

- Foram recolhidas no total mais de 800 ocorrências de adjetivos predicativos em SN, em anteposição e posposição nominal;

- Para efeitos estatísticos, reduzimos o corpus a 559 ocorrências, uma vez que tivemos de considerar a possibilidade do predicativo ocorrer tanto em anteposição como em 
Filol. lingüíst. port., n. 8, p. 145-189, 2006.

posposição. A redução só pode ser efetuada a partir do momento em que a categorização semântica dos dados estava completa.

- Foram efetuadas 3 rodadas da análise multirregressiva no programa estatístico VARBRUL:

a. 1a. rodada sem exclusão das ocorrências invariáveis (800 ocorrências);

b. 2a. rodada com exclusão das ocorrências invariáveis (559 ocorrências);

c. 3a. rodada com reamalgamento da categorização semântica (559 ocorrências).

Iremos nos concentrar aqui exclusivamente em (a), (b) e (c), dado o fato de que a rodada (a) esteja comprometida no seu aspecto semântico. Vamos nos deter em (b) para o escopo da análise no seu todo e em (c) para discorrermos a respeito de uma proposta de reordenação dos predicativos em categorias semânticas.

A análise binomial multirregressiva dos dados revelou, em ordem decrescente de importância, os seguintes grupos como sendo linguiisticamente significativos e que estariam influenciando a favor da anteposição dos predicativos:

a. Tipo de especificadores;

b. Categoria semântica dos predicativos;

c. A variável de singular e plural na presença ou ausência de especificadores.

d. A natureza do verbo;

e. Sexo;

f. O lugar argumental do predicativo no SN em relação aos complementos; 
SIMÕES, José da Silva. A anteposição dos adjetivos predicativos no português culto falado...

g. A natureza do nome.

Foram excluídos ao final da rodada os seguintes grupos, que aqui apresentaremos como não sendo lingüisticamente significativos:

h. Lugar argumental em relação ao verbo: anteposição/ posposição;

i. Unidade sintática onde aparece o predicativo: SN ou SP;

j. Faixa etária;

k. Presença ou ausência de especificadores e complementos;

1. Supercategorias dos predicativos: qualitativos, quantificadores e modalizadores.

3.1 Os grupos de fatores lingüisticamente significativos: a fronteira argumental do nome

Entre as variáveis independentes assinaladas acima, destacamos primeiramente as que se referem ao estudo do comportamento do adjetivo predicativo em anteposição em relação a suas fronteiras argumentais ligadas ao nome. Para tanto, observem-se os seguintes grupos de fatores:

a. Tipo de especificadores;

b. Marcas de singular e plural na presença ou ausência de especificadores e complementos;

c. A natureza do nome;

d. O lugar argumental do adjetivo nas fronteiras do SN;

e. A unidade sintática: SN e SP. 
Filol. lingüíst. port., n. 8, p. 145-189, 2006.

\section{a. Tipo de especificadores}

Em termos percentuais temos a seguinte distribuição de tipos de especificadores:

Tabela 1: Especificadores + Adjetivos

\begin{tabular}{lrr} 
Especificadores & \multicolumn{2}{c}{ Aplicações } \\
um/uma & 238 & $57 \%$ \\
a/o & 120 & $29 \%$ \\
esse/a & 13 & $3 \%$ \\
numeral & 5 & $1 \%$ \\
este/a & 2 & $0 \%$ \\
outro/a & 2 & $0 \%$ \\
muita/pouca & 1 & $0 \%$ \\
nenhum/a & 3 & $1 \%$ \\
aquele & 17 & $4 \%$ \\
algum/a & 4 & $1 \%$ \\
possessivos & 11 & $3 \%$ \\
única & 2 & $0 \%$ \\
vários/várias & 1 & $0 \%$ \\
tanto & 1 & $0 \%$ \\
& 420 &
\end{tabular}

Em função da não-aplicação da variação anteposição vs. posposição alguns fatores desse grupo foram reamalgamados afim de evitar os knock-outs na análise estatística. Reorganizado esse grupo, os dados ficaram assim: 
SIMÕES, José da Silva. A anteposição dos adjetivos predicativos no português culto falado...

Tabela 2: Especificadores + Adjetivos (reamalgamados para análise multirregressiva)

\begin{tabular}{lcccc}
$\quad$ Especificadores & $(\mathrm{A})^{1}$ & $(\mathbf{P})^{2}$ & Totais & Peso relativo \\
um/uma & 64 & 173 & 237 & 0.42 \\
& $27 \%$ & $73 \%$ & & \\
o/a & 56 & 59 & 115 & 0.61 \\
demonstrativos & $49 \%$ & $51 \%$ & & \\
(esse, este, aquele) & 10 & 22 & $32^{3}$ & 0.47 \\
nenhum & $31 \%$ & $69 \%$ & & \\
possessivos & 1 & 2 & 3 & 0.69 \\
\multirow{2}{*}{ Total } & $33 \%$ & $67 \%$ & & \\
& 10 & 1 & 11 & 0.95 \\
& $91 \%$ & $9 \%$ & & \\
& 141 & 257 & 398 &
\end{tabular}

Dentre os especificadores, embora o número de dados (10/398) não permita uma afirmação muito segura, a presença dos adjetivos possessivos (0.95) parece favorecer a anteposição. Confrontemos os seguintes exemplos:

(52) Suponho que talvez pela sua maior antiguidade no Brasil a imprensa escrita já chegou a essa sofisticação de oferecer veículos diferentes a públicos diferentes. (D2 SP 255: 963)

(53) Vê-se a aceitação da teorização estética em obras como seu pequeno e clássico filme "O Balé Mecânico". (EF SP 156: 237)

(54) Coisa que não ocorre em Belo Horizonte a despeito da sua íntima ligação com o Rio de Janeiro. (D2 SP 343:1588)

(55) E na tradução ele perde por causa da sua extraordinária beleza. (EF SP 156: 445)

e

(56) Também já existia suas modistas grandes aqui como La Saison, por exemplo (D2 SP 396: 793)

\footnotetext{
Anteposição (doravante A).

Posposição (doravante P)

As variantes este, esse e aquele foram reamalgamadas em um único grupo.
} 
Filol. lingüíst. port., n. 8, p. 145-189, 2006.

O exemplo (56) é o único com posposição do predicativo na presença de possessivos. Na verdade, podemos até afirmar que seus, em (56), não funciona verdadeiramente como um possessivo, se analisarmos o contexto mínimo que o acompanha. Pelo confronto, percebemos que os exemplos recolhidos poderiam muito bem ocorrer na posição não marcada, na posposição, mas a presença dos possessivos parece ser um determinante forte para o deslocamento dos predicativos em questão.

Por outro lado, a frequiência de predicativos em anteposição na presença de artigos definidos é bastante alta e bem balanceada $(0,61)$. Adiante comentamos melhor os pesos relativos e as frequiências principalmente dos adjetivos antepostos na presença do artigo definido no singular e no plural.

Com artigos indefinidos temos também uma grande porcentagem (64/398). E a seguir aos artigos definidos, apresentou-se como variante também bastante significativa dentro desse grupo de fatores. Logo a seguir temos os demonstrativos $(10 / 32=31 \%)$, e com reduzido número de ocorrência, os indefinidos nenhum/nenhuma (1/3 $=33 \%$ ).

\section{b. Marcas de singular e plural na presença ou ausência de especificadores e complementos}

\section{Tabela 3: Marcas de singular e plural na presença ou ausência} de especificadores e complementos

$\begin{array}{lccc} & \text { A } & \text { P } & \text { Peso relativo } \\ \text { sing. sem especificador } & 27 & 27 & 0.74 \\ \text { pl. sem especificador } & 50 \% & 50 \% & \\ & 29 & 70 & 0.44 \\ \text { sing. com especificador } & 29 \% & 71 \% & \\ & 116 & 240 & 0.46 \\ \text { pl. com especificador } & 33 \% & 67 \% & \\ & 25 & 25 & 0.60 \\ \text { Total } & 50 \% & 50 \% & \\ & 197 & 362 & \\ & 35 \% & 65 \% & \end{array}$


SIMÕES, José da Silva. A anteposição dos adjetivos predicativos no português culto falado...

Os pesos relativos entre si indicam que as ocorrências em singular sem especificadores favorecem a anteposição. Logo em seguida temos, então, os exemplos de plural com especificador (0.60), mas a prudência alerta-nos para o fato de que o grande número de ocorrências dos exemplos em singular com especificadores é bastante notória e significativa. A partir daí efetuamos um cruzamento de dados para saber qual o tipo de especificador que mais se sobressai no singular e no plural. Para tanto, temos a seguinte tabela:

\section{Tabela 4: Cruzamento do tipo de especificador com ausência/ presença de sg/pl}

\begin{tabular}{|c|c|c|c|c|c|c|c|c|c|c|c|c|c|}
\hline & & $\stackrel{\text { E }}{\text { E }}$ & & $\frac{\pi}{0}$ & & $\frac{\frac{\mathscr{v}}{\tilde{g}}}{\frac{\vec{v}}{\sigma}}$ & & 声 & & 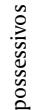 & & 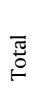 & \\
\hline \multirow[t]{3}{*}{ sg. sem especificador } & A & 0 & $0 \%$ & 0 & $0 \%$ & 0 & $0 \%$ & 0 & $0 \%$ & 0 & $0 \%$ & 0 & $0 \%$ \\
\hline & $\mathrm{P}$ & 0 & $0 \%$ & 0 & $0 \%$ & 0 & $0 \%$ & 0 & $0 \%$ & 0 & $0 \%$ & 0 & $0 \%$ \\
\hline & & 0 & $0 \%$ & 0 & & 0 & & 0 & & 0 & & 0 & \\
\hline \multirow[t]{3}{*}{ pl. sem especificador } & A & 0 & $0 \%$ & 2 & $33 \%$ & 0 & $0 \%$ & 0 & $0 \%$ & 0 & $0 \%$ & 2 & $25 \%$ \\
\hline & $\mathrm{P}$ & 0 & $0 \%$ & 4 & $67 \%$ & 2 & $100 \%$ & 0 & $0 \%$ & 0 & $0 \%$ & 6 & $75 \%$ \\
\hline & & 0 & & 6 & & 2 & & 0 & & 0 & & 8 & \\
\hline \multirow[t]{3}{*}{ sg. com especificador } & A & 64 & $27 \%$ & 36 & $42 \%$ & 7 & $30 \%$ & 1 & $33 \%$ & 7 & $100 \%$ & 115 & $33 \%$ \\
\hline & $\mathrm{P}$ & 169 & $73 \%$ & 49 & $58 \%$ & 16 & $70 \%$ & 2 & $67 \%$ & 0 & $0 \%$ & 236 & $67 \%$ \\
\hline & & 233 & & 85 & & 23 & & 3 & & 7 & & 351 & \\
\hline \multirow{3}{*}{ pl. com especificador } & A & 0 & $0 \%$ & 18 & $75 \%$ & 3 & $43 \%$ & 0 & $0 \%$ & 3 & $75 \%$ & 24 & $62 \%$ \\
\hline & $\mathrm{P}$ & 4 & $100 \%$ & 6 & $25 \%$ & 4 & $57 \%$ & 0 & $0 \%$ & 1 & $25 \%$ & 15 & $38 \%$ \\
\hline & & 4 & & 24 & & 7 & & 0 & & 4 & & 39 & \\
\hline \multirow[t]{3}{*}{ Total } & A & 64 & $27 \%$ & 56 & $49 \%$ & 10 & $31 \%$ & 1 & $33 \%$ & 10 & $91 \%$ & 141 & $35 \%$ \\
\hline & $P$ & 173 & $73 \%$ & 59 & $51 \%$ & 22 & $69 \%$ & 2 & $67 \%$ & 1 & $9 \%$ & 257 & $65 \%$ \\
\hline & & 237 & & 115 & & 32 & & 3 & & 11 & & 398 & \\
\hline
\end{tabular}

A partir daí notamos que os especificadores que mais favorecem a anteposição são os artigos definidos o/a tanto no singular (42\%) como no plural (75\%).

\section{c. A natureza do verbo}

Outro grupo de fatores que parece influir na anteposição é exatamente o grupo que trata da natureza do verbo. 
Filol. lingüíst. port., n. 8, p. 145-189, 2006.

Tabela 5: Natureza do Verbo

$\begin{array}{lcccc}\quad \text { Natureza do verbo } & \text { A } & \text { P } & \text { Total } & \text { Peso relativo } \\ \text { Verbo transitivo direto (biargumental) } & 73 & 149 & 222 & 0.48 \\ \text { Verbo de ligação } & 33 \% & 67 \% & & \\ & 47 & 96 & 143 & 0.51 \\ \text { Verbo transitivo indireto (biargumental) } & 33 \% & 67 \% & & \\ \text { Verbo apresentacional (Tem gente que...) } & 30 & 36 & 66 & 0.57 \\ \text { Verbo transitivo direto e indireto (verbo triargumental) } & 45 \% & 55 \% & & \\ & 18 & 38 & 56 & 0.44 \\ \text { Verbo intransitivo } & 32 \% & 68 \% & & 0.64 \\ & 13 & 13 & 26 & \\ \text { Verbo impessoal } & 14 & 50 \% & & 0.72 \\ \text { Total } & 54 \% & 46 \% & 26 & 0.16 \\ & 2 & 17 & 19 & \end{array}$

A supremacia desse grupo é exercida, sem dúvida, pela variante dos verbos intransitivos - alta porcentagem e alto peso relativo. Para melhor visualizarmos o resultado obtido, vejamos alguns exemplos:

(57) e aparece também uma belíssima senhora, uma belíssima senhora que era produtora (EF SP 153:?)

(58) Raul Roulin, célebre ator ligeiro e cantor de tangos, partiu para a América. (EF SP 153: 537)

(59) Tudo gira em torno do vil metal. (D2 SP 343: 738)

(60) Em se falando de teatro, é a interpretação do artista. Não adiantam infinitos recursos técnicos. (DID SP 161: 334)

(61) Por estranha coincidência passaram-se mais alguns anos e pegou fogo no mercado velho. (DID SP 208: 281)

Após a análise cuidadosa dos contextos acima, percebemos que o resultado estatístico está comprometido, já que outros fatores estão proporcionando aí a anteposição.

Em (58) o aposto, funcionando como qualificação explícita do referente, força o deslocamento para a posição pré-nominal - mais 
SIMÕES, José da Silva. A anteposição dos adjetivos predicativos no português culto falado...

adiante veremos que os predicativos qualitativos também constituem um fator preponderante na anteposição.

Já em (59) e (61), temos a presença de duas estruturas fraseológicas do português, uma coligação verbal: girar em torno de, que exige preposição, uma coligação nominal vil metal e uma coligação de regência adverbial por estranha coincidência. Em (60) e (61), o argumento da recorrência das expressões e seu uso cristalizado explicam o uso da anteposição.

No exemplo (60), temos outro fator "empurrando" o adjetivo para a anteposição: o sanduíche adjetival com um não-predicativo.

Excluídos esses casos, temos (57) como exemplo em que talvez a natureza do verbo aja a favor da variação. No entanto, precisamos ser cuidadosos, pois o qualitativo apresenta o valor de um intensificador - talvez pudéssemos até falar de uma intensificação exclusiva dos qualitativos, em oposição à atenuação.

Assim, consideramos o resultado estatístico como não sendo significativo no que toca os verbos intransitivos.

A seguir, temos o grupo dos verbos triargumentais (VTDI) com alta probabilidade $(0.64)$ e frequiência intermediária $(13 / 13=50 \%)$. Observemos então os seguintes exemplos:

(62) [Eu] acrescentaria apenas a esse, a esta série de filmes, dentro dessa mesma linha, os bons filmes policiais. (D2 255: 553)

(63) Mas alguns põem ênfase nesse eterno presente em que há forças ocultas. (EF SP 124: 161)

(64) A indústria começou então (...) para adaptar todo aquele imenso sistema cinematográfico aos novos tempos do cinema falado. (EF SP 153: 107)

Mais uma vez, os exemplos parecem desmentir uma possível influência da natureza do verbo na ordem do SN. Em (62), a grande extensão do SV tem sim uma organização interna, mas isso não influi diretamente no $\mathrm{SN}$ os novos tempos do cinema falado, no qual o que 
mais parece deslocar o adjetivo é, de um lado o valor semântico exclusivo de novo e sua dimensão silábica reduzida que sucumbiria sob uma outra ordenação. Há também aí um balanceamento na distribuição ( $\mathrm{SN}=\mathrm{A}+\mathrm{N}+\mathrm{SP}$ ) dos elementos. Por isso, podemos dizer que elementos mais pesados seguem o nome, enquanto elementos de menor dimensão o antecedem no português.

Em (63), dois outros elementos mais imediatos interferem na ordem: a presença do demonstrativo nesse e da relativa, o que leva a crer que também aqui se repete o exposto acima. $\mathrm{O}$ mesmo ocorre com (64), em que o elemento que segue o $\mathrm{N}$ é um não-predicativo.

Finalmente temos o fator de natureza verbal que, de certa forma, atua a favor da variação, os verbos transitivos diretos (73/ $222=33 \%$ ), com uma probabilidade de 0.48 , acompanhados dos verbos de ligação (0.51).

Uma vez assumido que os fatores que mais influenciam na ordem são os elementos que mais diretamente estão ligados com o fenômeno em questão, então podemos afirmar que tanto a natureza do verbo quanto a posição argumental do $S N$ na oração interagem de uma maneira menos intensa do que os elementos mais fronteiriços como os especificadores e os complementos. $\mathrm{Na}$ análise regressiva, foi excluído aquele que pela intuição parecia ser o grupo mais significativo no tocante a verbos: posição argumental em relação ao verbo. Mas, para efeito de saber onde se localizam em sua grande maioria os SNs adjetivados, observemos a seguinte tabela:

\section{Tabela 6: Lugar argumental em relação ao verbo}

$\begin{array}{lcccc} & \text { A } & \text { P } & & \text { Peso relativo } \\ \text { SN adjetivados anteposto ao verbo } & 16 & 17 & 33 & 0.56 \\ & 48 \% & 52 \% & & \\ \text { SN adjetivados posposto ao verbo } & 181 & 332 & 513 & 0.50 \\ & 35 \% & 65 \% & & \\ \text { Total } & 197 & 349 & 546 & \\ & 36 \% & 64 \% & & \end{array}$


SIMÕES, José da Silva. A anteposição dos adjetivos predicativos no português culto falado...

O resultado em percentagem (33 vs. 513!) confirma as expectativas de ocorrência de $\mathrm{SN}$ adjetivados em posição pós-verbal. Isso se deve evidentemente a questões de planejamento conversacional do falante, que repete na organização da oração o esquema básico do português SVO. Mesmo se excluirmos os dados referentes aos verbos apresentacionais e os impessoais que forçam a presença do SN adjetivado posposto, ainda assim teremos um resultado bastante alto para esse grupo de fatores.

\section{d. A natureza do Nome}

Outro grupo de fatores que se mostrou bastante significativo foi o grupo da natureza do nome. Para esse grupo criamos tão-somente as notações concreto e abstrato. Talvez numa análise mais cuidadosa das propriedades de $\mathrm{N}$ pudéssemos tirar conclusões mais efetivas a respeito do comportamento de adjetivos com o nome. Naturalmente, um estudo mais aprofundado sobre a relação entre $\mathrm{N}$ e Adj seria necessário aqui. No entanto, esperamos que a notação criada aqui não tenha influenciado demasiadamente no resultado estatístico.

\section{Tabela 7: Natureza do Nome}

$\begin{array}{lcccc} & \text { A } & \text { P } & & \text { Peso relativo } \\ \text { N abstrato } & 112 & 234 & 346 & 0.46 \\ & 32 \% & 68 \% & & \\ \text { N concreto } & 85 & 128 & & 0.57 \\ & 40 \% & 60 \% & & \\ \text { Total } & 197 & 362 & 559 & \\ & 35 \% & 65 \% & & \end{array}$

O resultado parece bastante balanceado entre ambos os tipos abstrato e concreto. Substantivos concretos com predicativos antepostos são mais frequientes em proporção, mas os abstratos ocorrem em maior número no geral. 
Filol. lingüíst. port., n. 8, p. 145-189, 2006.

Tabela 8: Cruzamento de Natureza do Nome x Categoria do Predicativo

\begin{tabular}{|c|c|c|c|c|c|c|c|}
\hline & & 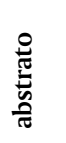 & & 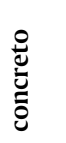 & & $\mathrm{T}$ & \\
\hline \multirow[t]{3}{*}{ Quantificador não-unidimensional } & A & 9 & $56 \%$ & 8 & $35 \%$ & 17 & $44 \%$ \\
\hline & $P$ & 7 & $44 \%$ & 15 & $65 \%$ & 22 & $56 \%$ \\
\hline & & 16 & & 23 & & 39 & \\
\hline \multirow[t]{3}{*}{ Aspectualizador definido } & A & 4 & $21 \%$ & 2 & $40 \%$ & 6 & $25 \%$ \\
\hline & $P$ & 15 & $79 \%$ & 3 & $60 \%$ & 18 & $75 \%$ \\
\hline & & 19 & & 5 & & 24 & \\
\hline \multirow[t]{3}{*}{ Qualitativo não-psicológico } & A & 31 & $26 \%$ & 54 & $43 \%$ & 85 & $34 \%$ \\
\hline & $P$ & 90 & $74 \%$ & 72 & $57 \%$ & 162 & $66 \%$ \\
\hline & & 121 & & 126 & & 247 & \\
\hline \multirow[t]{3}{*}{ Modalizador delimitador indefinido } & A & 2 & $13 \%$ & 2 & $33 \%$ & 4 & $18 \%$ \\
\hline & $P$ & 14 & $88 \%$ & 4 & $67 \%$ & 18 & $82 \%$ \\
\hline & & 16 & & 6 & & 22 & \\
\hline \multirow[t]{3}{*}{ Modalizador delimitador definido } & A & 7 & $25 \%$ & 2 & $22 \%$ & 9 & $24 \%$ \\
\hline & $P$ & 21 & $75 \%$ & 7 & $78 \%$ & 28 & $76 \%$ \\
\hline & & 28 & & 9 & & 37 & \\
\hline \multirow[t]{3}{*}{ Intensificadores } & A & 43 & $48 \%$ & 11 & $52 \%$ & 54 & $49 \%$ \\
\hline & $P$ & 46 & $52 \%$ & 10 & $48 \%$ & 56 & $51 \%$ \\
\hline & & 89 & & 21 & & 110 & \\
\hline \multirow[t]{3}{*}{ Modalizador epistêmico asseverativo } & A & 12 & $31 \%$ & 4 & $50 \%$ & 16 & $34 \%$ \\
\hline & $P$ & 27 & $69 \%$ & 4 & $50 \%$ & 31 & $66 \%$ \\
\hline & & 39 & & 8 & & 47 & \\
\hline \multirow{3}{*}{$\begin{array}{l}\text { Modalizador } \\
\text { assevarativo }\end{array}$} & A & 1 & $33 \%$ & 1 & $33 \%$ & 2 & $33 \%$ \\
\hline & $P$ & 2 & $67 \%$ & 2 & $67 \%$ & 4 & $67 \%$ \\
\hline & & 3 & & 3 & & 6 & \\
\hline \multirow[t]{3}{*}{ Qualitativo Psicológico } & A & 1 & $8 \%$ & 0 & $0 \%$ & 1 & $5 \%$ \\
\hline & $P$ & 12 & $92 \%$ & 6 & $100 \%$ & 18 & $95 \%$ \\
\hline & & 13 & & 6 & & 19 & \\
\hline \multirow[t]{3}{*}{ Quantificador unidimensional } & A & 2 & $100 \%$ & 1 & $17 \%$ & 3 & $38 \%$ \\
\hline & $P$ & 0 & $0 \%$ & 5 & $83 \%$ & 5 & $63 \%$ \\
\hline & & 2 & & 6 & & 8 & \\
\hline \multirow[t]{3}{*}{ Total } & A & 112 & $32 \%$ & 85 & $40 \%$ & 197 & $35 \%$ \\
\hline & $P$ & 234 & $68 \%$ & 128 & $60 \%$ & 362 & $65 \%$ \\
\hline & & 346 & & 213 & & 559 & \\
\hline
\end{tabular}

O cruzamento dos grupos natureza do nome e categoria dos predicativos indica que a intensificação se verifica mais com substantivos abstratos (43/54) e que em termos de quantificação temos os não-unidimensionais acompanhando com maior frequiência os subs- 
SIMÕES, José da Silva. A anteposição dos adjetivos predicativos no português culto falado...

tantivos abstratos. Todos os outros grupos cruzados indicam um certo balanceamento.

\section{e. Complementos: $\mathrm{O}$ lugar argumental dos predicativos}

Certamente, esse grupo de fatores é bastante significativo na questão da ordem do SN. Juntamente com o grupo dos especificadores, esse vai completar o conjunto sintático que importa para a ordenação. Inicialmente criamos os seguintes tokens para essa variável:

\section{Tabela 9: Tipos de complementos}

$\begin{array}{llcc}\text { a } & ([\mathrm{N}+\text { Prep }+\mathrm{N}]+\mathrm{Adj}) & 3 & 1 \% \\ \mathrm{~b} & \text { AN ou NA } & 389 & 69 \% \\ \mathrm{c} & (\mathrm{N}+[\mathrm{A}]+\text { Prep }+\mathrm{N}) & 51 & 9 \% \\ \mathrm{~d} & (\text { AN)A }+ \text { Que-Frase }) & 18 & 3 \% \\ \mathrm{e} & \text { ANA ou NAA com não-predicativo } & 16 & 3 \% \\ \mathrm{f} & (\text { AN }+ \text { Que-Frase }) \text { ou }(\mathrm{N}+\text { Que-Frase }+\mathrm{A}) & 12 & 2 \% \\ \mathrm{~g} & (\mathrm{NAA}(\mathrm{A})) & 10 & 2 \% \\ \mathrm{~h} & \{\mathrm{~N}\}+\text { Prep }+\mathrm{N}+\{\mathrm{A}\} & 10 & 2 \% \\ \mathrm{i} & (\mathrm{A}+[\mathrm{N}+\text { Prep }+\mathrm{N}]) & 54 & 10 \% \\ \mathrm{j} & \mathrm{N}+\text { não predicativo }(\sim \text { AN ou N } \sim \mathrm{A}) & 2 & 0 \% \\ \mathrm{k} & ((\mathrm{NA} \sim)+\mathrm{A}+\text { Que-Frase }) & 2 & 0 \% \\ \text { Total } & & 567 & \end{array}$

De forma a deixar mais clara a notação, oferecemos os seguintes exemplos:

$\mathrm{a}=(65)$ Eu acho trem assim o tipo de transporte gostoso. (D2 SP 255: 240)

$\mathrm{b}=(66)$ Bom artista é o que desempenha o papel na peça de acordo com o que ele está fazendo. (DID SP 234: 76)

$\mathrm{c}=(67)$ Então os testes deles possuem graus crescentes de dificuldades. (EF SP 377: 97)

$\mathrm{d}=(68)$ Existem três motivos clássicos pelos quais as pessoas retêm moeda. (EF SP 388: 25) 
Filol. lingüíst. port., n. 8, p. 145-189, 2006.

$\mathrm{e}=(69)$ Inclusive porque ela é um exemplo muito curioso de uma polêmica estabelecida num alto nível intelectual. (EF SP 156: 742) $\mathrm{f}=(70)$ A maioria dos bons artistas que nós temos hoje cursou escola de arte dramática. (D2 SP 333: 148)

$\mathrm{g}=(71) \mathrm{E}$ ao lado dos ricos (...) então, viceja (...) esse pequeno mundo de artesãos humildes e vivos (...) e freqüentemente aventureiros. (EF SP 153:254)

$\mathrm{h}=(72) \mathrm{O}$ artista (...) que no berro colocar o timbre de voz necessário para apresentação do espetáculo (DID SP 161: 622)

$\mathrm{i}=(73)$ Nós que tivemos a enorme realmente ventura de ser seus alunos (...) (EF SP 156: 260)

$\mathrm{j}=(74)$ Um bom recurso técnico também é um fator preponderante. (DID SP 161: 393)

$\mathrm{k}=(75)$ Aí o que está havendo aí é uma grande campanha publicitária para se vender um produto (...) (D2 SP 255: 430)

Naturalmente, por serem em sua maioria fatores knockout, os mesmos foram reamalgamados para três subgrupos dentro de uma nova variável dependente:

\section{Tabela 10: Tipo de complementos (reamalgamados)}

$\begin{array}{lcccc} & \text { A } & \text { P } & \text { Total } & \text { Peso relativo } \\ \text { somente NA ou AN (adjetivo) } & 129 & 274 & 403 & 0.46 \\ & 32 \% & 68 \% & & \\ \text { presença de Sintagma Preposicionado } & 56 & 68 & 124 & 0.63 \\ & 45 \% & 55 \% & & \\ \text { presença de Que-Frase }^{4} & 12 & 20 & 32 & 0.47 \\ \begin{array}{l}\text { (possessor phrase) } \\ \text { Total }\end{array} & 197 & 362 & 559 & \\ & 35 \% & 65 \% & & \end{array}$

4 Para este fator também consideramos as relativas introduzidas por preposições e as orações reduzidas de infinitivo (finais). 
SIMÕES, José da Silva. A anteposição dos adjetivos predicativos no português culto falado...

Pelo que ficou exposto até agora, por constituírem um elemento "pesado" dentro do SN, os demais complementos tendem a deslocar os predicativos para antes do $\mathrm{N}$, a fim de que haja um balanceamento entre os elementos que estão em torno do $\mathrm{N}$ como elemento central do SN. Os exemplos anteriormente citados comprovam bem essa intuição.

Um exemplo nos parece, no entanto, bastante singular em meio às nossas hipóteses:

(76) Um cara que ganha dez mil deve deixar uma quantidade de moeda por precaução guardada maior do que um cara que ganha mil e duzentos, certo? (EF SP 388: 295)

Observe-se a colocação de "guardada maior" posposto a todos os outros elementos do SN, contrariando "regras" básicas de organização. A ocorrência talvez tenha a sua explicação, se notarmos que os predicativos foram localizados em posição medial na oração, já que se trata de uma comparação. Assim a informatividade parece ter sido o elemento que forçou o deslocamento irregular dos predicativos.

As frequiências mostram que a presença de sintagma preposicionado e presença de Que-Frase são elementos importantes para a organização do SN. Uma observação a ser feita em relação à ausência de complementos (ou seja, somente NA ou AN) é a seguinte: na maioria das vezes em que o $\mathrm{N}$ vem acompanhado de um não-predicativo - estando este, por conseguinte, em posição pós-nominal -, o predicativo é deslocado para a posição anterior. Existe também certa liberdade na ordenação dos elementos quando da presença de SPs. Os exemplos (65), (67), (72) e (73) mostram essa flutuação do predicativo de acordo com o teor de informatividade nele contido e sua relação com o $\mathrm{N}$ que predica.

Efetuamos também o cruzamento dos grupos especificadores e complementos, para que pudéssemos observar o comportamento de uns em relação aos outros: 
Filol. lingüíst. port., n. 8, p. 145-189, 2006.

Tabela 11: Cruzamento dos grupos Especificadores x Complementos

\begin{tabular}{|c|c|c|c|c|c|c|c|c|c|c|c|c|c|}
\hline & & $\stackrel{\widetilde{\Xi}}{\Xi}$ & & $\frac{\pi}{0}$ & & 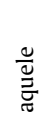 & & $\begin{array}{l}\text { E } \\
\text { 吾 }\end{array}$ & & 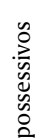 & & $\mathrm{T}$ & \\
\hline A & $\begin{array}{l}\text { Somente } \\
\text { adjetivo }\end{array}$ & 42 & $24 \%$ & 25 & $41 \%$ & 6 & $26 \%$ & 1 & $33 \%$ & 8 & $89 \%$ & 82 & $30 \%$ \\
\hline $\mathrm{P}$ & $\mathrm{T}$ & $\begin{array}{l}134 \\
176\end{array}$ & $76 \%$ & $\begin{array}{l}36 \\
61\end{array}$ & $59 \%$ & $\begin{array}{l}17 \\
23\end{array}$ & $74 \%$ & $\begin{array}{l}2 \\
3\end{array}$ & $67 \%$ & $\begin{array}{l}1 \\
9\end{array}$ & $11 \%$ & $\begin{array}{l}190 \\
272\end{array}$ & $70 \%$ \\
\hline A & $\begin{array}{l}\text { Presença de } \\
\text { Sintagma } \\
\text { Preposicionado }\end{array}$ & 20 & $41 \%$ & 24 & $56 \%$ & 3 & $38 \%$ & 0 & $0 \%$ & 2 & $100 \%$ & 49 & $48 \%$ \\
\hline$P$ & $\mathrm{~T}$ & $\begin{array}{l}29 \\
49\end{array}$ & $59 \%$ & $\begin{array}{l}19 \\
43\end{array}$ & $44 \%$ & $\begin{array}{l}5 \\
8\end{array}$ & $63 \%$ & $\begin{array}{l}0 \\
0\end{array}$ & $0 \%$ & $\begin{array}{l}0 \\
2\end{array}$ & $0 \%$ & $\begin{array}{c}53 \\
102\end{array}$ & $52 \%$ \\
\hline A & $\begin{array}{l}\text { Presença de } \\
\text { Que-Frase }^{5} \\
\text { (possessor phrase) }^{\text {poss }}\end{array}$ & 2 & $17 \%$ & 7 & $64 \%$ & 1 & $100 \%$ & 0 & $0 \%$ & 0 & $0 \%$ & 10 & $42 \%$ \\
\hline $\mathrm{P}$ & P 0000000 P & $\begin{array}{l}10 \\
12\end{array}$ & $83 \%$ & $\begin{array}{c}4 \\
11\end{array}$ & $36 \%$ & $\begin{array}{l}0 \\
1\end{array}$ & $0 \%$ & $\begin{array}{l}0 \\
0\end{array}$ & $0 \%$ & $\begin{array}{l}0 \\
0\end{array}$ & $0 \%$ & $\begin{array}{l}14 \\
24\end{array}$ & $58 \%$ \\
\hline $\begin{array}{l}A \\
P\end{array}$ & Total & $\begin{array}{c}64 \\
173 \\
237\end{array}$ & $\begin{array}{l}27 \% \\
73 \%\end{array}$ & $\begin{array}{c}56 \\
59 \\
115\end{array}$ & $\begin{array}{l}49 \% \\
51 \%\end{array}$ & $\begin{array}{l}10 \\
22 \\
32\end{array}$ & $\begin{array}{l}31 \% \\
69 \%\end{array}$ & $\begin{array}{l}1 \\
2 \\
3\end{array}$ & $\begin{array}{l}33 \% \\
67 \%\end{array}$ & $\begin{array}{c}10 \\
1 \\
11\end{array}$ & $\begin{array}{c}91 \% \\
9 \%\end{array}$ & $\begin{array}{l}141 \\
257 \\
398\end{array}$ & $\begin{array}{l}35 \% \\
65 \%\end{array}$ \\
\hline
\end{tabular}

O cruzamento entre especificadores e complementos revela uma alta ocorrência de adjetivos simples antepostos, quando co-ocorrem com possessivos (89\%). Na presença de sintagmas preposicionados a anteposição também se verifica significativa quando o adjetivo ocorre acompanhado seja de artigo definido (56\%), seja de artigo indefinido (41\%). Também é alta a anteposição do adjetivo, quando ocorre a presença de uma Que-Frase (possessor phrase) (64\%).

\section{f. Finalmente: A categoria dos predicativos}

Algumas conclusões foram tiradas até o momento sobre a anteposição. Foram apresentados todos os grupos de fatores selecionados na análise multirregressiva, com exceção do grupo sexo,

\footnotetext{
Para este fator também consideramos as relativas introduzidas por preposições e as orações reduzidas de infinitivo (finais).
} 
SIMÕES, José da Silva. A anteposição dos adjetivos predicativos no português culto falado...

sobre o qual falaremos em conjunto com outros fatores sociais em questão. Agora pretendemos discorrer brevemente a respeito do comportamento dos predicativos e a relação estabelecida entre os parâmetros semânticos e sintáticos. Ao final da primeira rodada sem a exclusão dos outros quase 200 exemplos cuja especificação falamos acima - o grupo de fatores categoria dos predicativos apresentou-se como sendo o grupo linguíístico mais significante. Já na segunda rodada - com a retirada dos dados citados -, o grupo da categoria dos predicativos foi excluído na análise regressiva. No entanto, o supergrupo dos predicativos - qualitativos, quantificadores e modalizadores - foi o segundo mais significativo, logo após o dos especificadores. Para visualizar melhor as frequiências, observem-se as seguintes tabelas:

\section{Tabela 12: Categoria dos adjetivos predicativos}

Quantificador não-unidimensional
Quantificador aspectualizador
Qualitativo não-psicológico
Modalizador delimitador indefinido
Modalizador delimitador definido
Quantificador intensificador
Modalizador epistêmico asseverativo
Modalizador epistêmico quase-asseverativo
Qualitativo psicológico
Quantificador unidimensional
Total

$\begin{array}{cccc}\text { A } & \mathbf{P} & & \text { Peso relativo } \\ 17 & 22 & 39 & 0.58 \\ 44 \% & 56 \% & & \\ 6 & 18 & 24 & 0.37 \\ 25 \% & 75 \% & & \\ 85 & 162 & 247 & 0.51 \\ 34 \% & 66 \% & & \\ 4 & 18 & 22 & 0.34 \\ 18 \% & 82 \% & & \\ 9 & 28 & 37 & 0.39 \\ 24 \% & 76 \% & & \\ 54 & 56 & 110 & 0.69 \\ 49 \% & 51 \% & & \\ 16 & 31 & 47 & 0.45 \\ 34 \% & 66 \% & & \\ 2 & 4 & 6 & 0.49 \\ 33 \% & 67 \% & & \\ 1 & 18 & 19 & 0.09 \\ 5 \% & 95 \% & & \\ 3 & 5 & 8 & 0.46 \\ 38 \% & 63 \% & & \\ 197 & 362 & 559 & \\ 35 \% & 65 \% & & \end{array}$


Filol. lingüíst. port., n. 8, p. 145-189, 2006.

É importante observar que por serem fatores knock-out, os predicativos deônticos e os aspectualizadores definidos foram excluídos da análise.

Os resultados da tabela 12 mostram que temos um grande número de predicativos intensificadores em anteposição (0.69). Em seguida temos os quantificadores não-unidimensionais (0.58) e os qualitativos não-psicológicos (0.51). Dentro dos modalizadores temos os asseverativos (0.45) e os quase-asseverativos (0.49).

Tabela 13: Supergrupo dos Predicativos

$\begin{array}{lcccc} & \text { A } & \mathbf{P} & \text { Total } & \text { Peso relativo } \\ \text { Adjetivos qualitativos } & 80 & 101 & 181 & 0.52 \\ \text { Adjetivos quantificadores } & 44 \% & 56 \% & & \\ & 86 & 180 & 166 & 0.50 \\ \text { Adjetivos modalizadores } & 32 \% & 68 \% & & \\ & 31 & 81 & 112 & 0.48 \\ \text { Total } & 28 \% & 72 \% & & \\ & 197 & 362 & 559 & \\ & 35 \% & 65 \% & & \end{array}$

Vale notar: a tabela que representa o supergrupo categoria dos predicativos segue o agrupamento proposto por Castilho (1992a).

A partir dos cruzamentos feitos anteriormente, podemos afirmar com segurança que, em termos semânticos, os intensificadores são a categoria que mais favorece a anteposição do adjetivo predicativo em português. Em geral, se seguirmos a ordenação proposta por Castilho (v. tabela 14), os dados comprovam que os quantificadores $(0.50)$ com os qualitativos (0.52) são as duas categorias que mais favorecem a anteposição.

Porém, se assumirmos as ressalvas feitas acima a respeito dos exemplos que flutuam de uma categoria para outra, e reagruparmos os predicativos segundo os critérios também adotados para os advérbios nos estudos publicados ao longo dos dois primeiros volumes da Gramática do Português Falado, teríamos a seguinte distribuição: 
SIMÕES, José da Silva. A anteposição dos adjetivos predicativos no português culto falado...

Tabela 14: Proposta de reorganização dos Predicativos

$\begin{array}{lcccc}\text { Quantificadores } & 20 & 27 & 47 & 0.56 \\ \text { (unidimensionais e não-unidimensionais) } & & & & \\ & 43 \% & 57 \% & & 0.36 \\ \text { Aspectualizadores definidos } & 6 & 18 & 24 & \\ & 25 \% & 75 \% & & 0.50 \\ \text { Qualitativos } & 85 & 162 & 247 & \\ \text { (não-psicológicos) } & & & & \\ & 34 \% & 66 \% & & 0.34 \\ \text { Modalizadores } & 32 & 99 & 131 & \\ \text { (epistêmicos asseverativos e quase-asseverativos, } & & & & \\ \text { delimitadores definidos e indefinidos, qualitativos } & & & & \\ \text { psicológicos) } & 24 \% & 76 \% & & \\ & 54 & 56 & 110 & 0.69 \\ \text { Intensificadores } & 49 \% & 51 \% & & \\ \text { Total } & 197 & 362 & 559 & \end{array}$

Assim a classe dos quantificadores compreenderia os unidimensionais e os não-unidimensionais. Os aspectualizadores e os intensificadores seriam deslocados cada um para uma categoria isolada. Os psicológicos, por predicarem sempre passando pelo viés do falante, deixando transparecem uma "crença" ou "opinião" explícitas, voltariam aos modalizadores. E os qualitativos só iriam comporse dos anteriormente chamados não-psicológicos.

Mas se ainda quisermos fazer uma distinção para os casos apresentados como limítrofes, veremos que, em sua grande maioria, os casos referem-se às proporções, às dimensões não palpáveis, instaladas no patamar de abstração do falante que cria segundo um parâmetro particular e pessoal um índice de proporção e de dimensão também bastante pessoal. Dessa forma, podemos dizer então que os exemplos citados de (37) a (51) estariam dentro do que poderíamos chamar de quantificadores psicológicos, uma possível subcategoria dos modalizadores, uma vez que estão voltados para o falante. Através dessa nova categoria tentamos englobar tanto os focalizadores de Ilari (1992) como os separativos de Ferris (1991). Observe-se a seguinte tabela: 
Filol. lingüíst. port., n. 8, p. 145-189, 2006.

Tabela 15: Quantificadores psicológicos

\begin{tabular}{|c|c|c|c|}
\hline & \multicolumn{2}{|c|}{ Proporcionais } & Atenuadores \\
\hline \multirow{4}{*}{$\begin{array}{l}\text { grande hobby } \\
\text { muita felicidade } \\
\text { imensa revolução } \\
\text { grandes problemas } \\
\text { da sociedade } \\
\text { grandes valores }\end{array}$} & Proporção numérica & $\begin{array}{l}\text { valor médio } \\
\text { valor simbólico }\end{array}$ & \multirow[t]{4}{*}{$\begin{array}{l}\text { pequenas } \\
\text { manifestações } \\
\text { esporádicas } \\
\text { mínima vocação }\end{array}$} \\
\hline & $\begin{array}{l}\text { Coincidência com } \\
\text { um protótipo }\end{array}$ & $\begin{array}{l}\text { bom ator } \\
\text { boa voz } \\
\text { verdadeiro } \\
\text { laboratório } \\
\text { boa italiana } \\
\text { má católica } \\
\end{array}$ & \\
\hline & Congruência & diferença exata & \\
\hline & Factualidade & situação real & \\
\hline
\end{tabular}

Essa reordenação, por servir apenas como teste, não é estanque, e por esse motivo é passível de reformulações. No entanto, talvez ela possa valer como reflexão a respeito da categorização semântica dos predicativos.

\section{g. Os Fatores Sociais}

Uma vez que todos os dados são oriundos das entrevistas transcritas do Projeto NURC-SP, não acrescentamos à nossa análise o fator escolaridade, pois todos os falantes possuíam grau universitário. Detemo-nos tão-somente ao fator sexo e idade.

Excluídas as ocorrências produzidas pelo documentador, podemos observar que há um índice maior de anteposição adjetival produzida pelos falantes do sexo masculino (114/188 contra 74/188 do sexo feminino). Isso se deve, em parte, ao fato de que há mais entrevistas com falantes do sexo masculino.

No cruzamento dos fatores sociais, percebemos que falantes do sexo feminino da terceira faixa etária tendem a usar anteposição com maior frequiência do que falantes masculinos da mesma faixa 
SIMÕES, José da Silva. A anteposição dos adjetivos predicativos no português culto falado...

etária. Já na segunda faixa etária, quem se sobressai são os falantes do sexo masculino.

Nas EF, os falantes da terceira faixa etária privilegiam a anteposição, principalmente falantes do sexo masculino. Nas entrevistas D2, os falantes masculinos da segunda faixa etária são os que mais usam a anteposição. Nos diálogos DID, os falantes do sexo feminino privilegiam a anteposição.

No geral, os dados estão balanceados em todos os três tipos de textos orais, embora a nossa intuição fosse a de que haveria maior ocorrência de anteposição nas EF. Quanto ao fator idade, podemos dizer que há maior número de ocorrências de anteposição entre os falantes de terceira idade, o que vem a indicar que a anteposição adjetival já deve ter sido mais privilegiada anteriormente do que atualmente. Isso não indica, no entanto, que o fenômeno esteja tornando-se linguiisticamente estigmatizado.

\section{CONCLUSÕES}

A análise feita acima, tanto de caráter qualitativo como quantitativo, permitiu-nos observar os seguintes resultados que explicam a ocorrência de anteposição de adjetivos em PB:

1. Não foram encontrados exemplos em anteposição dos adjetivos aspectualizadores definidos. Tal fato nos autoriza a reconhecer estes adjetivos como não-predicativos, uma vez que se apresentem como os /-prototípicos/ entre os predicativos, pois parecem estar semanticamente mais perto dos não-predicativos, assim como os dêiticos de tempo. Em geral, os aspectualizadores predicam indicando a frequiência com que um evento se reitera. Desse modo, eles normalmente estão ligados a N deverbais.

2. Sugerimos também, a partir das considerações de Connor Ferris (1991), que era preciso reconhecer a categoria dos adjetivos de qualificação separativa. Tal trabalho foi relevante para a nossa pesquisa, pois permitiu-nos visualizar uma nova possibilidade de leitu- 
ra dos adjetivos predicativos que transitam entre os quantificadores, os intensificadores e os modalizadores. Por serem adjetivos de referência temporal pontual e, portanto, dêiticos, e assim, meramente não-predicativos, achamos oportuno concentrarmo-nos tão-somente nos adjetivos aqui chamados separativos.

3. Em relação a processos, sentimentos e avaliações, foi difícil enxergar o nível de mensuração ou de quantificação. Portanto, achamos que talvez fosse adequado dissociar a intensificação da quantificação, pelo fato de a primeira apresentar-se como um fenômeno que deve ser entendido como autônomo à idéia de quantificação.

4. Observamos ainda que entre os especificadores, a presença dos adjetivos possessivos favorece a anteposição. Ainda quanto à presença de especificadores, notamos que os pesos relativos indicam que as ocorrências em singular sem especificadores favorecem a anteposição. Os artigos definidos, tanto no singular como no plural, principalmente quando acompanhados de complementos, são os especificadores que mais marcam anteposição.

7. No que se refere à categoria dos predicativos, os resultados mostram um grande número de predicativos intensificadores em anteposição, seguidos dos quantificadores não-unidimensionais e dos qualitativos não-psicológicos. Na categoria dos modalizadores, notamos que a anteposição se realiza mais com adjetivos do tipo asseverativos e os quase-asseverativos.

8. Com base nos cruzamentos de fatores, observamos que, em termos semânticos, os intensificadores são a categoria que mais favorece a anteposição do adjetivo predicativo no português brasileiro. Por outro lado, se seguirmos a ordenação proposta por Castilho, os dados comprovam que tanto os quantificadores como os qualitativos são as duas categorias que mais favorecem a anteposição.

9. A análise cruzada dos fatores sociais revelou que falantes do sexo feminino da terceira faixa etária tendem a usar anteposição com maior frequiência do que falantes masculinos da mesma faixa etária. Já na segunda faixa etária, quem se sobressai são os falantes do sexo masculino. Nas elocuções formais (EF), os falantes da terceira faixa etária 
SIMÕES, José da Silva. A anteposição dos adjetivos predicativos no português culto falado...

privilegiam a anteposição, principalmente os falantes do sexo masculino. Nos diálogos (D2), percebemos que a anteposição é mais selecionada pelos falantes masculinos da segunda faixa etária. Nos diálogos entre informante e documentador (DID), os falantes do sexo feminino privilegiam a anteposição. No conjunto, os dados estão balanceados em todos os três tipos de entrevistas, embora a nossa intuição fosse de que a maior ocorrência de anteposição se fizesse presente nas EF. No que se refere à idade dos falantes, percebemos que a anteposição de adjetivos acontece mais entre os falantes de terceira idade. Isso indica que a anteposição adjetival já deve ter sido mais privilegiada em outras épocas do que na década de 1970 quando foram feitas as entrevistas do NURC-SP. Porém, percebemos que o fenômeno não está linguiisticamente estigmatizado: os resultados quantitativos dos fatores analisados acima demonstram que a anteposição se mostra ainda bastante produtiva.

A idéia deste artigo foi a de propor uma entre muitas das possíveis interpretações a respeito da questão da anteposição dos adjetivos em português e não tem a pretensão de esgotar o assunto. O trabalho aqui apresentado antecede alguns estudos realizados sobre o assunto, tal como o artigo de Castilho (1993 e 1993a), versão revista de seu trabalho anterior (Castilho, 1992). Posteriormente, o tema foi retomado nos trabalhos de Nunes-Pemberton (1997) e Müller/Negrão/Nunes-Pemberton (2002). O artigo aqui apresentado visou apenas resgatar os estudos que fizemos (Simões, 1992) por ocasião do curso sobre a Sintaxe do Adjetivo oferecido pelo Prof. Dr. Ataliba Teixeira de Castilho em 1992.

\section{BIBLIOGRAFIA}

CASTILHO, Ataliba (Org.) (1986). A linguagem falada culta na cidade de São Paulo, v. I Elocuções formais. São Paulo: T.A. Queiroz/FAPESP.

; PRETTI, Dino (Org.). (1987). A linguagem falada culta na cidade de São Paulo, v. II Diálogos entre dois informantes. São Paulo: T.A. Queiroz/FAPESP. FAPESP.

. (Org.) (1990). Gramática do Português falado, v. I: A ordem. Campinas: Ed. Unicamp/ 
Filol. lingüíst. port., n. 8, p. 145-189, 2006.

(1992). Os Adjetivos Predicativos no Português Falado. São Paulo: FFLCH-USP, mimeografado.

; CASTILHO, C. M. M. (1993) Adjetivos predicativos no português falado, trabalho apresentado no VII Seminário da Gramática do Português Falado, mimeografado.

. (1993a) Adjetivos Predicativos. In: LETRAS, vol. 5, p. 122-43.

FERRIS, Connor (1991) Time reference in English adjectives and separative qualification. Linguistics, 29, Walter de Gruyter 1991, p. 569-90.

ILARI, Rodolfo (Org.) (1992). Gramática do Português falado, v. II: Níveis de Análise Linguiística. Campinas: Ed. Unicamp.

MÜLLER, Ana Lúcia; NEGRÃO, Esmeralda Vailati; NUNES-PEMBERTON, Gelza (2002) Adjetivos no português do Brasil: predicados, argumentos ou quantificadores? In: ABAURRE, Maria Bernardete M.; RODRIGUES, Angela C. S. (Org.). Gramática do Português Falado. v. VIII: Novos estudos descritivos. Campinas: Ed. Unicamp, p. 317-44.

NUNES-PEMBERTON, Gelza (1997). A anteposição dos adjetivos ao nome dentro do sintagma nominal. In: Anais de Seminários do GEL. Campinas: p. 150-6.

PRETI, Dino; URBANO, Hudinilson (Org.) (1988). A linguagem falada culta na cidade de São Paulo, vol. III - Entrevistas (Diálogos entre informante e documentador). São Paulo: T. A. Queiroz/FAPESP.

SCHERRE, Maria Marta Pereira (1991). A concordância de número nos predicativos e nos particípios passivos. In: A variação no português do Brasil, Organon, Revista do Instituto de Letras da Universidade Federal do Rio Grande do Sul, v. 5, n. 18.

SIMÕES, José da Silva (1992). A anteposição dos adjetivos predicativos no português falado: uma perspectiva quantificadora e crítica dos dados. São Paulo: FFLCH-USP, mimeografado.

TARALLO, Fernando (1990). A pesquisa sociolingüística. São Paulo: Ática, Série Princípios.

ABSTRACT: In this article, we discuss the anteposition of adjectives in spoken brazilian portuguese (bp) in the city of São Paulo, using data from the Projeto NURC-SP. This essay is based on the typology proposed by llari (1990 and 1992) and Castilho (1990) for the categorization of adverbs in spoken brazilian portuguese. The analysis of the anteposition of adjectives was also based on variation theory, taking into account a statistical analysis of the variables anteposition vs. postposition of predicative adjectives. Firstly, we present an overview of word order in brazilian portuguese (Tarallo, 1990). Secondly, we propose a categorization of the predicative adjectives in three types: quantifiers, aspectualizers and modalizers according to Castilho (1992a). Thirdly, we discuss the results of the statistical analysis and the cross-tabulation of the selected factors. Finally we present the factors that favour the anteposition of the predicative adjectives in bp.

KEYWORDS: Predicative adjectives; Spoken Brazilian Portuguese; Modalization operators; Functional grammar; Word order. 